\title{
KEANEKARAGAMAN JENIS TUMBUHAN PAKU-PAKUAN (PTERIDOPHYTA) PADA BERBAGAI UMUR LAHAN GAMBUT BEKAS KEBAKARAN DI DESA RASAU JAYA UMUM KABUPATEN KUBU RAYA
}

(Diversity of Types Ferns (Pteridophyta) In Various Age of Ex-Burned Peat Land In Rasau Jaya Umum Village, Kubu Raya District)

\author{
Ella kurniawati, Dwi Astiani, Iskandar \\ Fakultas Kehutanan Universitas Tanjungpura Jalan Imam Bonjol Pontianak 78124 \\ e-mail: ellakurniawati95@gmail.com
}

\begin{abstract}
The burning activity of peatlands in Kubu Raya Regency could kill various types of vegetation, one of which is ferns (Pteridophyta). Research on the species diversity of ferns needs to be execausted to obtain information or about the composition of the ferns species that present in peat ex-burn peat lands. This research was carried out at various ages sites (1, 2, 3 and 4 years) of ex-burn peat lands in Rasau Jaya Umum Village, Kubu Raya Regency. This study applyed survey metode with double plot technique, Plot laying using a purposive sampling methode, plot size was $5 \times 5 \mathrm{~m}$ divided into 25 sub-plots of $1 \times 1 \mathrm{~m}$ size.Three repetations were aplly made on each site. The results showed that on 1 year old ex-burn site were found 4 ferns species, paku ribu ribu (Lygodium microphyllum Cav.R.Br) paku cenceran (Neprolefis falcata Cap. C.Chr) paku lemiding (Stecchlanaena palustris Burm Bedd) and paku resam (Gleichenia linearis Burn Clarke) and 2,3,4, years old ex-burn peatland 3 species of ferns were found, namely paku cenceran (Neprolefis falcata Cap. C.Chr) paku lemiding (Stecchlanaena palustris Burm Bedd) and paku resam (Gleichenia linearis Burn Clarke). From the results of the study concluded that the diversity of species of ferns at various ages (1,2, 3 and 4 years) of ex-burn peatlands in Rasau Jaya Umum Village, Kubu Raya Regency were not relatively similiar.
\end{abstract}

Keywords: ex-burn peat land, fern, species diversity.

\section{PENDAHULUAN}

Aktivitas pembakaran lahan gambut khususnya di Kabupaten Kubu Raya dilakukan masyarakat setempat untuk penyiapan lahan pertanian. Untuk mempercepat tersedianya unsur hara dalam budidaya tanaman masyarakat pada umumnya melakukan sistem tebas bakar. Sebagian besar wilayah Rasau Jaya merupakan lahan gambut. Di kecamatan ini terdapat banyak sekali kasus kebakaran hutan dan lahan yang sangat sering terjadi pada tiap tahunnya. Lahan yang dibakar itu selain areal pertanian juga berada di kawasan perkebunan dan sangat berdampak terhadap keanekaragaman jenis tumbuhan, selain itu pemulihan tumbuhan setelah kebakaran akan memakan waktu lama dan akan sering terhambat bila kebakaran terulang. Kerusakan ekosistem akibat kebakaran berpeluang menghabiskan aneka jenis vegetasi, khususnya yang tidak mampu menghadapi perubahan keadaan tempat tumbuhnya.

Tumbuhan paku (Pteridophyta) merupakan suatu divisi yang 
anggotanya sudah berkormus yaitu tubuhnya dengan nyata dapat dibedakan dalam tiga bagian pokoknya, yaitu akar, batang dan daun. Paku-pakuan merupakan bagian dari keanekaragaman hayati dan merupakan komunitas tumbuhan yang memiliki fungsi ekologis yang cukup penting di dalam ekosistem lahan gambut bekas terbakar, Paku pakuan (pteridophyta) termasuk kedalam tumbuhan bawah perlu dipelajari karena tumbuhan bawah tersebut merupakan tumbuhan indikator dan tumbuhan pionir sebagai penutup tanah dan penting dalam pencampuran serasah serta pembentukan humus.

Berdasarkan uraian di atas, perlu dilakukan penelitian tentang keanekaragaman jenis paku pakuan karena sejauh ini masih kurangnya informasi atau data awal tentang susunan (komposisi jenis) dan bentuk (struktur) vegetasi yang ada pada beragai umur lahan gambut bekas kebakaran di desa Rasau Jaya Umum Kabupaten Kubu Raya.

\section{METODOLOGI PENELITIAN}

Penelitian ini dilakukan dengan menggunakan metode survey dengan menggunakan teknik petak ganda. Peletakan petak akan di letakan pada berbagai umur lahan bekas kebakaran dengan menggunakan metode purposive sampling, yaitu diletakan pada berbagai umur lahan bekas kebakaran tahun 2018, 2017, 2016, dan 2014 yang di temui jenis paku - pakuan. Ukuran petak yang di gunakan yaitu 5 x $5 \mathrm{~m}$ yang dibagi kedalam 25 sub petak dengan ukuran 1 x $1 \mathrm{~m}$. Jumlah petak yang di buat masing masing 3 petak pada berbagai umur lahan gambut bekas kebakaran.Selain tumbuhan paku pakuan tumbuhan bawah yang ada di dalam petak juga di lakukan pencatatan.

HASIL DAN PEMBAHASAN

Hasil penelitian menunjukan bahwa pada berbagai umur lahan gambut bekas kebakaran tahun 2018 ditemukan 4 jenis tumbuhan paku pakuan diantaranya paku ribu ribu (Lygodium microphyllum Cav.R.Br) paku cenceran (Neprolefis falcata Cap. C.Chr) paku lemiding (Stecchlanaena palustris Burm Bedd) dan paku resam (Gleichenia linearis Burn Clarke). Pada lahan gambut bekas kebakaran tahun 2017, 2016, dan 2014 masing masing di temukan 3 jenis paku yang sama yaitu (Neprolefis falcata Cap. C.Chr) paku lemiding (Stecchlanaena palustris Burm Bedd) dan paku resam (Gleichenia linearis Burn Clarke). Dari hasil penelitian dapat di simpulkan bahwa keanekaragaman jenis paku-pakuan pada lahan gambut bekas kebakaran tahun 2018, 2017, 2016, dan 2014 di desa Rasau Jaya Umum Kabupaten Kubu Raya relatif sama. Hasil lengkap dari jenis paku-pakuan di setiap umur bekas kebakaran disajikan pada tabel 1 . 
Tabel 1. Tumbuhan paku pakuan yang di temukan dan habitat tumbuhnya.

\begin{tabular}{|c|c|c|c|c|}
\hline \multirow{2}{*}{\multicolumn{5}{|c|}{$\begin{array}{l}\text { No Nama Lokal } \\
\text { Kebakaran tahun } 2018\end{array}$}} \\
\hline & & & & \\
\hline 1 & Paku Ribu ribu & $\begin{array}{l}\text { Lygodium microphyllum (Cav.) } \\
\mathrm{R.Br}\end{array}$ & Schizaeaceae & Teresterial \\
\hline 2 & Paku Cenceran & Neprolefis falcata (Cap.) C.Chr & Driopteridaceae & Teresterial \\
\hline 3 & Paku Lemiding & $\begin{array}{l}\text { Stecchlanaena palustris (Burm) } \\
\text { Bedd. }\end{array}$ & Gleicheniales & Teresterial \\
\hline 4 & Paku Resam & $\begin{array}{l}\text { Gleichenia linearis } \\
\text { Charke. }\end{array}$ & Aspleniaceae & Teresterial \\
\hline \multicolumn{5}{|c|}{ Kebakaran tahun 2017} \\
\hline 1 & Paku Cenceran & Neprolefis falcata (Cap.) C.Chr & Driopteridaceae & Teresterial \\
\hline 2 & Paku Lemiding & $\begin{array}{l}\text { Stecchlanaena palustris (Burm) } \\
\text { Bedd. }\end{array}$ & Gleicheniales & Teresterial \\
\hline 3 & Paku Resam & $\begin{array}{l}\text { Gleichenia linearis } \\
\text { Charke. }\end{array}$ & Aspleniaceae & Teresterial \\
\hline \multicolumn{5}{|c|}{ Kebakaran tahun 2016} \\
\hline 1 & Paku Cenceran & Neprolefis falcata (Cap.) C.Chr & Driopteridaceae & Teresterial \\
\hline 2 & Paku Lemiding & $\begin{array}{l}\text { Stecchlanaena palustris (Burm) } \\
\text { Bedd. }\end{array}$ & Gleicheniales & Teresterial \\
\hline 3 & Paku Resam & $\begin{array}{l}\text { Gleichenia linearis } \\
\text { Charke. }\end{array}$ & Aspleniaceae & Teresterial \\
\hline \multicolumn{5}{|c|}{ Kebakaran tahun 2014} \\
\hline 1 & Paku Cenceran & Neprolefis falcata (Cap.) C.Chr & Driopteridaceae & Teresterial \\
\hline 2 & Paku Lemiding & $\begin{array}{l}\text { Stecchlanaena palustris (Burm) } \\
\text { Bedd. }\end{array}$ & Gleicheniales & Teresterial \\
\hline 3 & Paku Resam & $\begin{array}{l}\text { Gleichenia } \\
\text { Charke. }\end{array}$ & Aspleniaceae & Teresterial \\
\hline
\end{tabular}

1. Indeks Nilai Penting (INP) Komunitas Paku Pakuan Pada Berbagai Umur Lahan Bekas Kebakaran di Desa Rasau Jaya Umum

Indeks Nilai Penting (INP) adalah parameter kuantitatif yang digunakan untuk menyatatakan tingkat penguasaan spesies-spesies dalam suatu komunitas (Indrianto, 2006). Menurut Soerianegara dan Indrawan (1982), suatu jenis memiliki peran pada suatu komunitas dicirikan dengan nilai penting yang tertinggi karena merupakan jumlah dari kepadatan relatif (KR) dan frekuensi (FR). Semakin tinggi indeks nilai penting suatu jenis maka semakin tinggi penguasaannya didalam suatu komunitas tempat jenis tersebut tumbuh. Analisis data dilakukan untuk mengetahui keanekaragaman jenis tumbuhan pakupakuan pada berbagai umur lahan bekas kebakaran dengan menggunakan parameter kerapatan jenis, indeks nilai penting (INP), indeks dominansi (C), indeks keanekaragaman jenis $\left(\mathrm{H}^{\prime}\right)$, indeks kelimpahan jenis (e), dan indeks kekayaan jenis (d).

Indeks nilai penting dari setiap jenis paku-pakuan diberbagai umur lahan bekas kebakaran di sajikan pada tabel 2, tabel 3, dan tabel 4 . 
Tabel 2. Analisis kerapatan jenis, Indeks nilai penting (INP).

\begin{tabular}{lllcc}
\hline No & Jenis & Kerapatan/ha & Kerapatan Relatif & INP \\
\hline & Kebakaran tahun 2018 & & & \\
1 & Lygodium microphyllum & 666,67 & 1,02 & 8,17 \\
2 & Stecchlanaena palustris & 35466,66 & 54,51 & 65,22 \\
3 & Gleichenia linearis & 16,800 & 25,82 & 36,53 \\
4 & Neprolefis falcata & 2,000 & 3,07 & 13,79 \\
& Jumlah & & & 123,71 \\
& Kebakaran tahun 2017 & & & \\
1 & Stecchlanaena palustris & 13066,66 & 10,40 & 25,40 \\
2 & Gleichenia linearis & 46266,66 & 36,84 & 51,84 \\
3 & Neprolefis falcata & 54133,33 & 43,10 & 58,10 \\
& Jumlah & & & 135,34 \\
& Kebakaran tahun 2016 & & & \\
1 & Stecchlanaena palustris & 4266,66 & 3,17 & 19,84 \\
2 & Gleichenia linearis & 3613,33 & 26,88 & 43,55 \\
3 & Neprolefis falcata & 86533,33 & 64,38 & 81,05 \\
& Jumlah & & & 144,44 \\
& Kebakaran tahun 2014 & & & \\
1 & Stecchlanaena palustris & 1600 & 0,94 & 12,71 \\
2 & Gleichenia linearis & 1733,33 & 1,02 & 12,13 \\
3 & Neprolefis falcata & 160266,66 & 94,57 & 112,22 \\
& Jumlah & & 131,84 \\
\hline
\end{tabular}

Nilai kerapatan tertinggi yang didapat dari banyaknya jumlah individu dalam areal seluas $0,0075 \mathrm{Ha}$ pada lahan bekas kebakaran adalah jenis dengan Neprolefis falcata dengan tingkat kerapatan 160266,77 individu/ha dan nilai kerapatan relatif tertinggi adalah jenis Neprolefis falcata dengan tingkat kerapatan 94,57 individu/ha pada umur lahan bekas kebakarantahun 2016. Nilai kerapatan terendah adalah jenis Stecchlanaena palustris dengan tingkat kerapatan 1600 individu/ha dan nilai kerapatan relatif terendah adalah jenis Stecchlanaena palustris dengan tingkat kerapatan 94,57 individu/ha pada umur lahan bekas kebakaran tahun 2014.

Berdasarkan hasil analisis data yang di lakukan, tingkat penguasaan tertinggi pada lahan bekas kebakaran adalah jenis $112,22 \%$. Tingginya nilai INP pada jenis
Neprolefis falcata menunjukan bahwa jenis ini menjadi penentu pada komunitas (ekosistem) pada berbagai umur lahan bekas kebakaran tahun 2014. Hal ini di buktikan dengan ditemukannya jenis paku ini pada hampir setiap petak pengamatan. Sedangkan nilai INP terendah adalah jenis Lygodium microphyllum $8,17 \%$. Rendahnya nilai INP pada jenis ini menunjukan bahwa jenis ini tidak menjadi penentu pada (ekosistem) pada erbagai umur lahan bekas kebakaran tahun 2018 . Hal ini di buktikan dengan ditemukannya jenis paku ini hanya pada satu petak pengamatan.

Tingginya nilai INP dipengaruhi oleh faktor genetik yang baik dan juga sangat di pengaruhi oleh interaksinya terhadap lingkungan seperti kondisi tanah, iklim, mikroorganisme dan juga kompetisi dengan organisme lain, dengan kata lain 
tumbuh - tumbuhan yang mempunyai adaptasi yang tinggilah yang bisa hidup mendominasi di dalam suatu kawasan.

\section{Indeks Nilai dominansi (C), Indeks} keanekaragaman jenis ( $\left.\mathrm{H}^{\prime}\right)$, indeks kekeayaan jenis (e), dan indeks kelimpahan jenis (D) Paku Pakuan Pada Berbagai Umur Lahan Bekas Kebakaran di Desa Rasau Jaya Umum.

Indeks Dominansi (C) di gunakan untuk menentukan dominansi suatu jenis dalam suatu komunitas. Adapun kriteria dalam menentukan dominansi menurut Indeks Simpon ID = 0 menujukan indeks dominansi rendah atau tidak ada satu spesies yang mendominansi terhadap jenis lainya, sedangkan ID $=1$ menunjukan dominansi tinggi atau terhadap spesies yang mendominansi jenis spesies yang lainya.

Indeks keanekaragaman jenis ( $\left.\mathrm{H}^{\prime}\right)$ di gunakan untuk mengukur stabilitas komunitas, yaitu kemampuan suatu komunitas untuk menjaga dirinya agar tetap stabil meskipun ada gangguan tehadap komponennya. Suatu komunitas di katakan memiliki keanekaragaman jenis yang tinggi jika komunitas tersebut tersusun banyak jenis, sebaiknya suatu komunitas di katakan memiliki keanekaragaman jenis yang rendah jika komunitas itu disusun oleh sedikit spesies (Tujudki et al. 2014)

Indeks kelimpahan jenis dipengaruhi oleh indeks keanekaragaman jenis dan jumlah jenis yang di temukan di dalam suatu area. Nilai indeks kelimpahan jenis berada diantara $0-1$, jika nilai kelimpahan semakin mendekati 1 maka kelimpahan semakin tinggi. Berdasarkan analisis data indeks kelimpahan jenis paku-pakuan pada pada berbagai umur lahan bekas kebakaran berkisar antara 0,44 sampai 1,24. hal ini menunjukan bahwa kekayaan jenis paku-pakuan pada lahan areal bekas kebakaran di desa Rasau Jaya Umum Kabupaten Kubu Raya termasuk rendah sampai sedang.

Hasil pengukuran rekapitulasi indeks nilai dominansi (C), Indeks keanekaragaman jenis (H'), indeks kekeayaan jenis (e), dan indeks kelimpahan jenis pada areal bekas kebakaran tahun 2018, 2017, 2016 dan 2014 dapat dilihat pada Tabel 3.

Tabel 3. Rekapitulasi indeks nilai dominansi (C), Indeks keanekaragaman jenis $\left(H^{\prime}\right)$, indeks kekeayaan jenis (e), dan indeks kelimpahan jenis pada areal bekas kebakaran tahun 2018, 2017, 2016 dan 2014.

\begin{tabular}{llcccc}
\hline No & Lokasi & C & H' & e & D \\
\hline 1 & Kebakaran Tahun 2018 & 0,17 & 0,56 & 0,93 & 3,63 \\
2 & Kebakaran Tahun 2017 & 0,19 & 0,59 & 1,24 & 2,66 \\
3 & Kebakaran Tahun 2016 & 0,24 & 0,45 & 0,94 & 2,67 \\
4 & Kebakaran Tahun 2014 & 0,35 & 0,21 & 0,45 & 2,68 \\
\hline
\end{tabular}


Berdasrkan analisis data diketahui rata-rata indeks didominansi jenis pakupakuan pada berbagai umur lahan bekas kebakaran, berkisar antara 0,17 sampai 0,35. Berdasarkan kriteria penentuan dominansi dapat di katakan bahwa jenis paku-pakuan pada keempat lokasi menunjukan bahwa semakin tua umur lahan bekas kebakaran maka dominansi paku pakuan semakin tinggi.

Berdasarkan hasil perhitungan indeks keanekaragaman jenis paku-pakuan pada lahan gambut bekas kebakaran berkisar antara 0,21 sampai 0,59. Nilai keanekaragaman jenis tumbuhan pakupakuan pada keempat lokasi tersebut tergolong rendah sampai sedang karena $\mathrm{H}^{\prime}$ $<1$. Keanekaragaman jenis sangat dipengaruhi oleh kondisi tempat tumbuh. Kebakaran hutan yang pernah terjadi pada keempat lokasi tersebut bisa saja mempengaruhi keanekaragaman jenis paku -pakuan tersebut.

Indeks kelimpahan jenis (e) dipengaruhi oleh indeks keanekaragaman jenis dan jumlah jenis yang di temukan di dalam suatu area. Nilai indeks kelimpahan jenis berada diantara $0-1$, jika nilai kelimpahan semakin mendekati 1 maka kelimpahan semakin tinggi. Berdasarkan analisis data indeks kelimpahan jenis paku-pakuan pada pada berbagai umur lahan bekas kebakaran berkisar antara 0,44 sampai 1,24. hal ini menunjukan bahwa kekayaan jenis paku-pakuan pada lahan areal bekas kebakaran di desa Rasau Jaya Umum Kabupaten Kubu Raya termasuk rendah sampai sedang.

Indeks kekayaan jenis (d) merupakan jumlah individu suatu jenis yang ditemukan selama pengamatan. Indeks kekayaan jenis berbanding lurus dengan indeks keanekaragaman jenis. Berdasarkan hasil analisis data untuk tumbuhan paku pada keempat lokasi penelitian yang mempunyai tutupan lahan yang hampir sama, daapat di ketahui nilai indeks kekayaan jenis paku-pakuan berkisar antara 2,66 sampai 3,62 karena berbanding lurus dengan nilai keanekaragaman maka kekayaan jenis paku pakuan pada lahan bekas kebakaran di Desa Rasau Jaya Umum Kabupaten Kubu Raya tinggi.

\section{Analisis Tempat Tumbuh}

Kondisi tempat tumbuh pada pakupakuan seperti suhu tanah tanah, kelembaban udara, intensitas tanah dan $\mathrm{pH}$ tanah serta tinggi muka air pada berbagai umur lahan bekas kebakaran (Tabel 4).

Tabel 4. Rata rata hasil pengukuran kondisi tempat tumbuh pada pada berbagai umur lahan bekas kebakaran di Desa Rasau Jaya Umum Rasau Jaya Umum

\begin{tabular}{|c|c|c|c|c|}
\hline $\begin{array}{l}\text { Kondisi } \\
\text { Tumbuh }\end{array}$ & $\begin{array}{c}\text { Kebakaran } \\
\text { Tahun } 2018\end{array}$ & $\begin{array}{c}\text { Kebakaran } \\
\text { Tahun } 2017\end{array}$ & $\begin{array}{c}\text { Kebakaran } \\
\text { Tahun } 2016\end{array}$ & $\begin{array}{l}\text { Kebakaran } \\
\text { Tahun } 2014\end{array}$ \\
\hline $\operatorname{Suhu}\left({ }^{\circ} \mathrm{C}\right)$ & 36,73 & 35,83 & 36,26 & 36,85 \\
\hline Kelembaban tanah(\%) & 25,06 & 71,61 & 51,33 & 75 \\
\hline Kelembaban udara (\%) & 51,7 & 65,61 & 65,68 & 63,35 \\
\hline Intensitas cahaya $(\mathrm{cd})$ & 7182,84 & 5999,5 & 5598,16 & 5215,5 \\
\hline ph tanah $(\mathrm{pH})$ & 4,16 & 4,13 & 4,06 & 4,01 \\
\hline TMA & 0,74 & 0,72 & 0,81 & 0,85 \\
\hline
\end{tabular}


Rata rata hasil pengukuran pada berbagai umur lahan bekas kebakaran di desa Rasau Jaya Umum Kabupaten Kubu Raya dapat dilihat pada tabel 4, menyatakan suhu tanah pada berbagai umur lahan bekas kebakaran berkisar antara $\quad 35,83^{\circ} \mathrm{C}$ sampai $36,85^{\circ} \mathrm{C}$. Kelembaban tanah berkisar antara 25,06\% sampai $71 \%$. Kelembaban udara berkisar antara $51,7 \%$ sampai $65,68 \%$. intensitas cahaya matahari berkisar antara 5215,5cd sampai 7182,84cd. $\mathrm{pH}$ berkisar 401 sampai 4,16. TMA berkisar antara 0,72 sampai 0,85 .

Hasil pengukuran kelembaban tanah pada umur lahan bekas kebakaran tahun 2018 memiliki kelembaban tanah paling rendah karena pada saat pelaksanaan penelitian sedang musim kemarau sedangkan pada tahun 2017, 2016 dan 2014 sudah memasuki musim penghujan.

Kelembaban udara pada lahan gambut bekas kebakaran 2018 berbeda dengan tahun 2017, 2016 dan 2014 ini dipengaruhi oleh keadaan tapak pada tahun 2018 yang merupakan lahan gambut baru terbakar. Hal ini juga terjadi pada rata rata hasil pengukuran intensitas cahaya matahari yang dipengaruhi oleh keadaan tapak lahan gambut baru terbakar sehingga vegetasi yang tumbuh pada lahan ini cenderung masih sedikit dan didominasi tumbuhan tingkat bawah sehingga intensitas cahaya matahari lebih banyak dibanding beberapa lokasi tahun sebelumnya.

\section{KESIMPULAN}

Hasil penelitian keanekaragaman jenis paku-pakuan pada berbagai umur lahan bekas kebakaran di Desa Rasau Jaya
Umum Kabupaten Kubu Raya Kalimantan Barat menunjukan bahwa

1. Pada areal bekas kebakaran umur 1 tahun ditemukan 4 jenis tumbuhan paku pakuan diantaranya paku ribu ribu (Lygodium microphyllum Cav.R.Br) paku cenceran (Neprolefis falcata Cap. C.Chr) paku lemiding (Stecchlanaena palustris Burm Bedd) dan paku resam (Gleichenia linearis Burn Clarke). Pada lahan gambut bekas kebakaran umur ( 2, 3 dan 4 tahun) masing masing di temukan 3 jenis paku yang sama yaitu (Neprolefis falcata Cap. C.Chr) paku lemiding (Stecchlanaena palustris Burm Bedd) dan paku resam (Gleichenia linearis Burn Clarke). Dari hasil penelitian dapat di simpulkan bahwa keanekaragaman jenis pakupakuan pada berbagai umur (1, 2, 3 dan 4 tahun) lahan gambut bekas kebakaran di di Desa Rasau Jaya Umum Kabupaten Kubu Raya relatif sama.

2. Semua jenis paku pakuan yang di temukan pada berbagai umur lahan bekas kebakaran di Desa Rasau Jaya Umum Kabupaten Kubu Raya Kalimantan Barat, tumbuh dengan parameter faktor abiotik sebagai berikut

Kisaran beberapa kondisi tapak antara menyatakan suhu tanah pada berbagai umur lahan bekas kebakaran berkisar antara $35,83^{\circ} \mathrm{C}$ sampai $36,85^{\circ} \mathrm{C}$. kelembaban tanah berkisar antara $25,06 \%$ sampai $71 \%$. Kelembaban udara berkisar antara $51,7 \%$ sampai $65,68 \%$. intensitas cahaya matahari berkisar antara 5215,5cd sampai 7182,84cd. pH 
berkisar 401 sampai 4,16. TMA berkisar antara 0,72 sampai 0,85 .

\section{Saran}

Melihat sedikitnya keanekaragaman jenis paku-pakuan yang di temukan pada berbagai umurlahan bekas kebakaran di Desa Rasau Jaya Umum Kabupaten Kubu Raya, maka perlu adanya pemanfaatan jenis paku-pakuan agar lebih bernilai ekonomi.

\section{DAFTAR PUSTAKA}

Arini D, Kinho J. 2012. Keragaman Jenis Tumbuhan Paku (Pteridophyta) di Cagar Alam Gunung Ambang Sulawesi Utara. Info BPK Manado 2(1) : 17-40.

Betty J, Linda L, Lovadi I. 2015. Inventarisasi Jenis Paku pakuan (Pteridophyta) Terestrial di Hutan Dusun Tauk Kecamatan Air Besar Kabupaten Landak, Protobiont 4(1): 94-102.

Indrianto. 2006. Ekologi Hutan, Jakarta: PT. Bumi Aksara.

Indriyanto. 2006. Laju infiltrasi pada lahan gambut yang dipengaruhi air tanah (studi kasus Sei Ara dalam Kecamatan Sei Raya Kabupaten Kubu Raya).Jurnal Belian, volume (1): 90-103.

Katili. 2013. Deskripsi pola penyebaran dan faktor bioekologis tumbuhan paku (Pteridophyta) di kawasan Cagar Alam Gunung Ambang Kabupaten Bolaang Mongondow Timur. Jurnal Saintek 7(1) :35-41.

Khamalia I, Herawatiningsih R, Ardian H. 2018. Keanekaragaman jenis pakupakuan di Kaswasan IUPHHK-HTI PT. Bhatara Alam Lestari Kabupaten Mempawah. Jurnal Hutan Lestari 6(3): 510-518.
Kinho J. 2011. Keanekaragaman Jenis Tumbuhan Paku di Taman Nasional Aketajawe-Lolobata. Balai Penelitian Kehutanan Manado. Manado.

Media Indonesia, 2011. Lahan Gambut Marak Dibakar Kalbar Siaga. MI Online

http://www.mediaindonesia.com/rea d/2011/03/09/208800/127/101/Laha n-Gambut Marak-Dibakar-KalbarSiaga-II

Odum EP. 1993. Dasar-Dasar Ekologi. Terjemahan Oleh Yogyakarta: Gadja Mada University Press.

Rosanti D, 2013. Tipe vegetasi hutan gambut bekas kebakaran Desa Kedaton Kabupaten Ogan Komering Ilir, Sainmatika 10(2):2533

Rismunandar dan Ekowati, 1991. Tanaman Hias Paku Pakuan, Panebar Swadaya, Jakarta.

Simbolon H, 2004. Proses awal pemulihan lahan gambut Kelampangan Kalimantan Tengah pasca kebakaran hutan desember 1997 dan september 2001, Berita Biologi 7(3):145-154.

Soerianegara, I dan A. Indrawan 1982. Ekologi Hutan Indonesia. Departemen Manajemen Hutan Fakultas Kehutanan Institusi Pertanian Bogor, Bogor.

Suraida, Susanti, Amriyanto, R. 2013. Keanekaragaman Tumbuhan Paku (Pteridophyta) di Taman Hutan Kenali Kota Jambi. Prosiding Semirata FMIPA Universitas Lampung.

Syafei, Eden Surasana. (1990). Pengantar Ekologi Tumbuhan. Bandung: ITB 
Syaufina L. 2008. Kebakaran Hutan dan Lahan di Indonesia. Malang: Bayu media

Ratih D. 2002. Keanakragaman Jenis Tumbuhan Paku Di Kawasan Air Terjun Montel Desa Colo Kabupaten Kudus (skripsi). Semarang: Universitas Negeri Semarang

Rosanti Dewi. 2013. Tipe Vegetasi Hutan Rawa Gambut Bekas Kebakaran. Sainmatika Volume 10: No 10 September 2016. 25-33

Raven, P.H., R.F. Evert dan S.E. Eichhorn. 1992. Biology of Plant. Word Publisher. New York.

Stren, K.R. 1992. Introductory Plant Biology. Wm. C Brown Publisher Bubuque. Lowa

Tim Ad Hoc, 2008. Pemanfaatan Lahan Gambut Untuk Transmigrasi.

Tjitrosoepomo. 2009. Taksonomi Umum(Dasar-dasar Taksonomi Tumbuhan).Yogyakarta: UGM Press

Tjitrosoepomo, Gembong. 1994. Taksonomi Tumbuhan Thallophyta, Schizophyta, Bryophyta, Pteridophyta. Yogyakarta:UGM Press.

Tjitrosoepomo. 2005. Taksonomi Tumbuhan (Schizophyta, Thallophyta, Bryophyta, Pteridophyta). Gajah Mada University Press: Yogyakarta

Tujudki K, Ningsih B, Toknok. 2014. Keanekaragaman jenis tumbuhan obat pada Kawasan Hutan Lindung di Desa Tindoli Kecamatan Pamona Tenggara Kabupaten Poso. Jurnal Warta Rimba 2(1): 120-128.
Widhiastuti, R., Aththhorik, T.A., dan Sari, W.D. 2006. Struktur Dan Komposisi Tumbuhan Paku-Pakuan Di Kawasan Hutan Gunung Sinabung Kabupaten Karo. Junal Biologi Sumatera. 2(8): 38-41 